\title{
Ingestion of saliva during carbohydrate feeding by Lutzomyia longipalpis (Diptera; Psychodidae)
}

\section{Reginaldo R Cavalcante, Marcos H Pereira*, Jorge M Freitas*, Nelder deF Gontjo*/+}

\author{
Departamento de Parasitologia e Microbiologia, CCS, Universidade Federal do Piauí, Teresina, PI, Brasil \\ *Departamento de Parasitologia, ICB, Universidade Federal de Minas Gerais, Cx. Postal 486, 31270-901 Belo Horizonte, \\ MG, Brasil
}

\begin{abstract}
The aim of this study was to obtain experimental evidence that phlebotomine saliva is actually ingested during the carbohydrate ingestion phase (before and after blood digestion). The ingestion of carbohydrate was simulated as it occurs in the field by offering the insects balls of cotton soaked in sucrose, sucrose crystals or orange juice cells. The results obtained here showed that ingestion occurred under each condition investigated, as indicated by the presence of apyrase, an enzyme used as a marker to detect saliva in the insect gut and/or carbohydrate sources. Saliva ingestion by phlebotomine during the carbohydrate ingestion phase is important to explain how it could promote starch digestion and to trigger Leishmania promastigotes to follow a differentiation pathway as proposed previously by some authors.
\end{abstract}

Key words: Lutzomyia longipalpis - carbohydrate ingestion - saliva ingestion

Lutzomyia longipalpis is the main vector of Leishmania infantum, the etiological agent of visceral leishmaniasis in South America (Lainson \& Rangel 2005). As well as the other phlebotomine species, adult females of the sand fly Lu. longipalpis are hematophagous. Adults of both sexes take sugar meals, which are stored in the foregut diverticulum (Tang \& Ward 1998). The sugar meal passes from the diverticulum to the anterior midgut, where it is digested and absorbed (Dillon \& el-Kordy 1997, Gontijo et al. 1998). Sugar meals provide the necessary energy source for these flies, without which they live only a few days after emergence.

The enzyme alpha-amylase, probably responsible for starch digestion in Lu. longipalpis, is exclusively salivary. As proposed by Ribeiro et al. (2000), it could be implicated in digestion of starch granules usually ingested by the sand flies during plant piercing (Schlein \& Jacobson 2000). Moreover, saliva could also participate in Leishmania metacyclogenesis by triggering these parasites to follow a differentiation pathway after blood digestion (Charlab \& Ribeiro 1993, Charlab et al. 1995). In each case saliva must be ingested at the right moment to be able to act in starch granules and in developing promastigotes inside the phlebotomine gut.

Despite the importance of saliva, up to now its ingestion by phlebotomine sand flies during the carbohydrate ingestion phase (after the ending of the blood digestion) was only one assumption of some authors. The aim of this study was to obtain experimental evidences to confirm saliva ingestion during this period. To approach this

Financial support: $\mathrm{CNPq}$

+Corresponding author: nelder@icb.ufmg.br

Received 25 October 2005

Accepted 16 January 2006 question, carbohydrate feeding was simulated the way it occurs in the field.

The presence of saliva in each type of solution or substrate offered, as well as inside the insect diverticulum or gut, was investigated using the enzyme apyrase as a marker. This enzyme is present in the saliva of hematophagous insects and has an important role in prevention of platelet aggregation by catalyzing ADP or ATP hydrolysis to AMP and inorganic phosphate (Ribeiro \& Francischetti 2003). The inorganic phosphate liberated can easily be measured by colorimetric methods.

\section{MATERIALS AND METHODS}

All experiments were performed using female $L u$. longipalpis (from Teresina, Piauí, Brazil) maintained in a closed colony (Modi \& Tesh 1983). The females used in the assays were 3-5 days old and had not been fed before the experiments were carried out.

Inorganic phosphate assay - Inorganic phosphate was measured using a commercial kit Labtest ${ }^{\circledR}$ code 042, based on the method described by Baginski et al. (1967). The kit reagents were added to tubes each containing 1.2 $\mathrm{ml}$ of sample according to the manufacturer's instructions (see protocols described below). Readings were made on a spectrophotometer at a wavelength of $650 \mathrm{~nm}$.

Apyrase assay on cotton balls - Cotton balls weighing approximately $7 \mathrm{mg}$ were soaked in $50 \mu \mathrm{l}$ of $30 \%$ sucrose or the same volume of $0.45 \% \mathrm{NaCl}$. Both the sucrose solution and that of $\mathrm{NaCl}$ contained bovine serum albumin (BSA) at a concentration of $1 \mathrm{mg} / \mathrm{ml}$ to stabilise the apyrase. Three balls were offered to 20 females for approximately $1 \mathrm{~h}$ inside a Barraud cage of dimensions 28 $\mathrm{cm} \times 18 \mathrm{~cm} \times 18 \mathrm{~cm}$. At the end of this period, each ball was transferred to microcentrifuge tubes containing $0.2 \mathrm{ml}$ of apyrase assay buffer $\mathrm{pH} 8(50 \mathrm{mM}$ Tris/ $\mathrm{HCl}$ buffer containing $1 \mathrm{mM} \mathrm{CaCl}_{2}, 2.5 \mathrm{mM} \mathrm{ADP}$ and $100 \mathrm{mM} \mathrm{NaCl}$ ) and incubated for $3 \mathrm{~h}$ at $30^{\circ} \mathrm{C}$. At the end of the incubation period $1 \mathrm{ml}$ of distilled water was added to each tube, 
which was then centrifuged at $10000 \mathrm{~g}$ for $2 \mathrm{~min}$ at room temperature. Six hundred microliters of supernatant were then transferred to another tube and mixed with $0.6 \mathrm{ml}$ of distilled water. This material $(1.2 \mathrm{ml})$ was used in inorganic phosphate content assays as described previously. As a control, cotton balls, not exposed to female phlebotomines, were processed as described above.

Apyrase assay on sucrose crystals - Ten unfed females that never had fed were transferred to a Barraud cage with an atmosphere of $100 \%$ humidity. After they were presented with cotton balls soaked in pure water for $1 \mathrm{~h}$, five sucrose crystals weighing approximately $8 \mathrm{mg}$ were introduced into the cage and left for $30 \mathrm{~min}$. After this time, each crystal was removed and transferred to a microcentrifuge tube containing $0.05 \mathrm{ml}$ of $0.8 \%$ saline and BSA at $1 \mathrm{mg} / \mathrm{ml}$. The assay commenced when $0.2 \mathrm{ml}$ of apyrase assay buffer were added to each tube, which was incubated at $30^{\circ} \mathrm{C}$ for $3 \mathrm{~h}$. The rest of the procedure was similar to that described previously.

Apyrase assay in the diverticulum and midgut - Between 10-30 females were introduced into a Barraud cage containing three cotton balls soaked with sucrose or $\mathrm{NaCl}$. After a period that varied from $30 \mathrm{~min}$ to $1 \mathrm{~h}$, the insects were removed and dissected to extract the diverticulum or midgut. For females fed on sucrose, the apyrase assay was done on the diverticulum, while for those fed on $\mathrm{NaCl}$ the midgut was used. Only organs of fed females were used in these assays. The dissected organs were transferred to $0.05 \mathrm{ml}$ of $0.8 \%$ saline containing BSA $1 \mathrm{mg} / \mathrm{ml}$ and homogenized using a microhomogenizer. Two hundred microliters of apyrase test buffer were added to the preparation when the microhomogenizers were washed in this buffer and incubated for $1 \mathrm{~h}$ at $30^{\circ} \mathrm{C}$. The rest of the procedure was similar to that already described. As a control, organs from unfed females were dissected and submitted to the same protocol.

Apyrase assay on orange juice cells - Juice cells obtained from orange segments of about the same size and shape were washed in distilled water and dried on absorbent paper. Two cells were then introduced into a cage containing 20 females and left for $1 \mathrm{~h}$. After this period, they were transferred to a tube containing $0.05 \mathrm{ml}$ of $0.8 \%$ saline including $1 \mathrm{mg} / \mathrm{ml} \mathrm{BSA}$ and homogenized. The as- say commenced with the addition of $0.2 \mathrm{ml}$ of apyrase assay buffer and tubes were incubated for $3 \mathrm{~h}$ at $30^{\circ} \mathrm{C}$. The rest of the procedure was as described previously. A blank prepared with juice cells not visited by females was provided in order to discount any phosphate already present.

\section{RESULTS AND DISCUSSION}

The assay results are shown in the Table. Saliva ingestion occurred under each condition investigated, as indicated by the presence of apyrase.

It is known that phlebotomines ingest carbohydrates in different ways. Although they must pierce vegetable tissue when they take sap from leaves or fruit, this is not necessary when they find nectar or secretions from plantfeeding insects, since these sugars lie exposed. Even when these secretions are dried up, they can be ingested after being solubilized probably by the saliva (Tang \& Ward 1998).

During the present study every way a phlebotomine uses to ingest carbohydrates was simulated to investigate whether saliva was ingested. The ingestion of insect secretions and nectar was simulated using small balls of cotton soaked in sucrose. The sucrose-soaked cotton balls provided immediate access to the solution without being necessary for the insects to pierce plant tissue with their mouthparts. Feeding on dried secretions was simulated by offering the phlebotomines sucrose crystals. In order to simulate sap ingestion by perforation of plant tissues, the insects were presented with juice cells obtained from orange segments. In this case, the only way for phlebotomines to ingest juice was to penetrate the cell walls with their mouthparts

Results are shown in the Table. Saliva ingestion occurred under each condition investigated, as indicated by the higher presence of inorganic phosphate due to apyrase action. Independently of the apirase activity, the concentration of phosphate ions is especially higher in the midgut and in the orange juice cells. This explains why the absorbance measured in the respective controls is higher.

Analysis of the data presented in the Table reveals that most of the saliva deposited on the cotton balls containing sugar or saline was ingested by the females and reached the phlebotomine gut.

TABLE

Presence of inorganic phosphate \pm standard deviation at the feeding site or in the diverticule and midguts of female Lutzomyia longipalpis after ingesting liquids from cotton balls, sucrose crystals or orange juice cells

\begin{tabular}{lcc}
\hline Apyrase detection site & A $650 \mathrm{~nm}$ & $\mathrm{n}$ \\
\hline In cotton balls soaked in sucrose, after these had been fed on by females & $0.057 \pm 0.039(0.005 \pm 0.004)$ & 18 \\
In diverticula of females that had fed on cotton balls soaked in sucrose & $0.216 \pm 0.221(0.030 \pm 0.044)$ & 15 \\
In cotton balls soaked in NaCl, after these had been fed on by females & $0.039 \pm 0.030(0.010 \pm 0.009)$ & 19 \\
In midguts of females that had fed on cotton balls soaked in NaCl & $0.348 \pm 0.275(0.149 \pm 0.107)$ & 16 \\
In sucrose crystals presented to females & $0.016 \pm 0.017(0.003 \pm 0.002)$ & 18 \\
In orange juice cells presented to females & $0.341 \pm 0.146(0.182 \pm 0.054)$ & 18 \\
\hline
\end{tabular}

The absorvance values shown in parentheses correspond to those obtained in the experimental controls. The means were significantly different from the respective controls $(\mathrm{P}<0.05$ by Student's $\mathrm{T}$ test). The n-numbers refer to both, experimental and control objects. 
The ingestion of liquids containing a small concentration of $\mathrm{NaCl}$ was also investigated. According to Schlein and Warburg (1985), and Tang and Ward (1998), the presence of low saline concentrations causes liquid to pass directly to the gut without entering the diverticulum. Although it is not known whether phlebotomines ingest salt solutions in nature, this possibility should not be ignored.

Saliva from $L u$. longipalpis appears to be involved in the modulation of metacyclogenesis in Leishmania. Charlab and Ribeiro (1993) and Charlab et al. (1995) described such a factor present in saliva that could affect the development of L. infantum (syn. L. chagasi) in culture medium in absence of hemin, a molecule derived from haemoglobin digestion. Since the effect of saliva is inhibited by the presence of hemin (Charlab \& Ribeiro 1995), one might speculate that saliva would only act after blood digestion was complete and hemin eliminated. The results presented in the Table confirm the presumption that saliva can enter in contact with promastigotes at the right moment in order to influenciate the fine control of metacyclogenesis in the Lu. longipalpis gut, as proposed by Charlab and Ribeiro (1993) and Charlab et al. (1995).

In nature, it is known that phlebotomines ingest plant sap, aphid and coccid secretions, and floral nectar (Chaniotis 1974, Alexander \& Usma 1994, Cameron et al. 1995a, b, Petts et al. 1997). Sucrose and starch are the principal carbohydrates present in plants that can be digested by the enzymes of Lu. longipalpis. In this species sucrose is digested by an alpha-glucosidase that is present only in the midgut (Gontijo et al. 1998) and starch is digested by an alpha-amylase that is exclusively salivary (Ribeiro et al. 2000). Since starch granules are commonly ingested by phlebotomines when they feed on plants (Schlein \& Jacobson 2000) saliva ingestion is probably the only natural way that alpha-amylase is brought into contact with starch in the gut of these insects.

\section{REFERENCES}

Alexander B, Usma MC 1994. Potential sugar sources of Lutzomyia youngi (Diptera: Psychodidae) in a Colombian coffee plantation. Ann Trop Med Parasitol 88: 543-549.

Baginsky ES, Foà PP, Zak B 1967. Microdetermination of inorganic phosphate, phospholipids, and total phosphate in biologic materials. Clin Chem 13: 326-332.

Cameron MM, Milligan PJM, Llanos-Cuentas A, Davies CR 1995a. An association between phlebotomine sandflies and aphids in the Peruvian Andes. Med Vet Entomol 9: 127-132.

Cameron MM, Pessoa FAC, Vasconcelos AW, Ward RD 1995b.
Sugar meal sources for the phlebotomine sandfly Lutzomyia longipalpis in Ceará, Brazil. Med Vet Entomol 9: 263-272.

Chaniotis B 1974. Sugar-feeding behavior of Lutzomyia trapidoi (Diptera: Psychodidae) under experimental conditions. $J$ Med Entomol 11: 73-79.

Charlab R, Ribeiro JMC 1993. Cytostatic effect of Lutzomyia longipalpis salivary gland homogenates on Leishmania parasites. Am J Trop Med Hyg 48: 831-838.

Charlab R, Tesh RB, Rowton ED, Ribeiro JMC 1995. Leishmania amazonensis: sensitivity of different promastigote morphotypes to salivary gland homogenates of the sand fly Lutzomyia longipalpis. Exp Parasitol 80: 167-175.

Dillon RJ, el-Kordy E 1997. Carbohydrate digestion in sandflies: alpha-glucosidase activity in the midgut of Phlebotonus langeroni. Comp Biochem Physiol B Biochem Mol Biol 116: 35-40.

Gontijo NF, Almeida-Silva S, Williams P, Mares-Guia ML, Melo MN 1998. Lutzomyia longipalpis: $\mathrm{pH}$ in the gut, digestive glycosidases, and their relationship with Leishmania development. Exp Parasitol 90: 212-219.

Lainson R, Rangel EF 2005. Lutzomyia longipalpis and the ecoepidemiology of American visceral leishmaniosis, with particular reference to Brazil - A review. Mem Int Oswaldo Cruz 100: 811-827.

Modi GB, Tech RB 1983. A simple technique for mass rearing Lutzomyia longipalpis and Phlebotomus papatasi (Diptera: Psychodidae) in the laboratory. J Med Entomol 5: 568-569.

Petts SL, Tang Y, Ward RD 1997. Nectar from a wax plant, Hoya sp, as a carbohydrate source for Lutzomyia longipalpis (Diptera: Psychodidae). Ann Trop Med Parasitol 4: 443446.

Ribeiro JM, Francischetti IM 2003. Role of arthropod saliva in blood feeding: sialome and post-sialome perspectives. Annu Rev Entomol 48: 73-88.

Ribeiro JMC, Rowton ED, Charlab R 2000. Salivary amylase activity of the phlebotomine sand fly, Lutzomyia longipalpis. Insect Biochem Mol Biol 30: 271-277.

Schlein Y, Jacobson RL 2000. Photosynthesis modulates the plant feeding of Phlebotomus papatasi (Diptera: Psychodidae). J Med Entomol 37: 319-324.

Schlein Y, Warburg A 1985. Feeding Behavior, midgut distension and ovarian development in Phlebotomus papatasi (Diptera: Psychodidae). J Insect Physiol 31: 47-51.

Tang Y, Ward RD 1998. Sugar feeding and fluid destination control in the phlebotomine sandfly Lutzomyia longipalpis (Diptera: Psychodidae). Med Vet Entomol 12: 13-19. 